A cut-off score was exceeded in an additionally prescribed PCA3 test. $\mathrm{PBx}$ was performed but histological examination revealed no evidence of PCa but prostate inflammation.

Abstract P3-S1.04 Table 1 Abnormal prostate cancer markers in a man with symptomatic $C$ trachomatis infection

\begin{tabular}{llll}
\hline & & \multicolumn{2}{l}{ Follow-up visits } \\
\cline { 3 - 4 } & First visit & 1 month & 3 months \\
\hline CT infection, tested by RT-PSR & Positive & Negative & Negative \\
Symptomatic & Yes & No & No \\
Digital rectal examination & Abnormal & Abnormal & Abnormal \\
WBCs, counted in hpf & $30-40$ & $0-2$ & $0-1$ \\
PSA test, 0-4 ng/ml & 13.9 Abnormal & 9.8 Abnormal & 1.5 Normal \\
PCA3 test, a cut-off score of 35 & & 38 Abnormal & \\
Prostate biopsy, to diagnose cancer & & Negative & \\
\hline
\end{tabular}

Conclusions Further studies to evaluate the time course of prostatitis/STIs on PrCa risk, particularly among a young cohort of men, have been warranted. New diagnostic markers are needed to investigate the pathways between the acquisition of CT and its impact on the prostate. This is the first report on detection of abnormal PSA and PCA3 tests in a Chlamydia-infected man suffering from LUTS, while no PrCa was histologically detected.

\section{P3-S1.05 INCIDENCE OF STI IN PATIENTS WITH CHRONIC PROSTATITIS}

doi:10.1136/sextrans-2011-050108.405

A Khaikova, S Sohar, V Kazlouskaya. Gomel State Medical University, Gomel, Belgium

Chronic prostatitis is a common problem among male patients. Some authors indicate that $30-40 \%$ of males have chronic prostatitis when they are $20-40$ years old. Last years the tendency to begin at the earlier age is seen in patients with prostatitis. STI should be excluded while examining of patients with prostatitis. We observed 96 sexually active men with chronic prostatitis (middle age $34.2 \pm 12.7$ years). All patients where checked up for STI. Microscopy and cultural method where used to diagnose gonorrhoea and trichomonas infection, PCR for chlamydia and herpes infection and Mycoplasma IST test system to diagnose mycoplasma infection. STI where founded in 44 patents (45.8\%). Neisseria gonorrhoea was founded in 10 patients (10.4\%), Trichominiasis vaginalis-in two patients (2,0\%), Mycoplasma hominis-in seven patients (7.3\%), Herpes genitalis-in two patients (2.0\%), Chlamydia trachomatis - in 23 patients (23.9\%). Still in $54.2 \%$ of patients the reason remained unknown. Patient with STI should be recommended to check up for all STI. As far as association with STI is quite common it is necessary to study their possible role in the development of chronic prostatitis. Chlamydia trachomatis infection seems to be associated with chronic prostatitis more commonly.

\section{P3-S1.06 ABSTRACT WITHDRAWN}

\section{P3-S1.07 CHLAMYDIA TRACHOMATIS SEROVAR DISTRIBUTION AND OTHER SEXUALLY TRANSMITTED COINFECTIONS IN SUBJECTS ATTENDING A STD OUTPATIENTS CLINIC IN ITALY}

doi:10.1136/sextrans-2011-050108.407

A Marangoni, M Donati, A D’Antuono, A Di Francesco, F Ostanello, C Foschi, P Nardini, N Banzola, R Cevenini. University of Bologna, Bologna, Italy

Background Chlamydia trachomatis is the leading cause of bacterial sexually transmitted diseases (STDs) in industrialised countries. omp1 (ompA), the gene encoding the major outer membrane protein (MOMP), has been widely used for molecular epidemiology, because it contains four spaced variable domains.

Methods A total of 1625 patients attending the STD Outpatients Clinic of St. Orsola University Hospital of Bologna, Italy were enrolled for this study. Each patient was clinically visited, bled in order to perform serological tests, than three urethral or endocervical swabs were obtained. Two swabs were cultured for the detection of $C$ trachomatis and Neisseria gonorrhoeae, whereas the third was stored at $-80^{\circ} \mathrm{C}$. When a positive result was obtained by $C$ trachomatis culture, the corresponding frozen sample was withdrawn, its DNA was extracted by VERSANT kPCR SP Module (Siemens Healthcare Diagnostics Inc.) and used as a template for omp1 gene fragment amplification. PCR products were purified and both strands were sequenced. Nucleotide sequences were compared to omp1 sequences using the BLAST search tool at the National Center for Biotechnology Information. The sequences were manually aligned using BioEdit (version 7.0.0) software. $\chi^{2}$ Test was used and a $p$ value of $<0.05$ was considered statistically significant.

Results C trachomatis was detected in 103 out of 1625 (6.3\%) swabs by culture. Prevalence was significantly higher in men $(p<0.01)$, with 60 positives out of 525 tested (11.4\%), than in women (43/ $1100 ; 3.9 \%)$, as well as presence of clinical symptoms: $81.7 \%(49 / 60)$ of infected men and $44.2 \%$ of infected women (19/43) were symptomatic. Also prevalence of STD coinfections was significantly higher $(p<0.01)$ in men $(35 / 60 ; 58.3 \%)$ than in women $(8 / 43$; $18.6 \%$ ). In our population the most common serovar was $\mathrm{E}$, with a prevalence of $38.8 \%$, followed by G $(23.3 \%)$, F (13.5\%), D/Da $(11.6 \%)$, and $J(4.8 \%)$. Statistically significant differences $(p=0.042)$

Abstract P3-S1.07 Table 1 Primary demographic, epidemiological, and clinical data and rates of infection with $C$ trachomatis serovars for male and female patients

\begin{tabular}{|c|c|c|c|}
\hline & \multicolumn{2}{|c|}{ Sex No $(\%)$ of patients } & \multirow[b]{2}{*}{$\mathrm{p}$ Value $\left(\chi^{2}\right.$ test $)$} \\
\hline & Males & Female & \\
\hline \multicolumn{4}{|c|}{ Place of birth } \\
\hline Italy & $42(70.0)$ & $22(51.2)$ & \multirow[t]{2}{*}{0.052} \\
\hline Other & $18(30.0)$ & $21(48.8)$ & \\
\hline \multicolumn{4}{|c|}{ Symptoms } \\
\hline Yes & $49(81.7)$ & $19(44.2)$ & \multirow[t]{2}{*}{$0.000^{*}$} \\
\hline No & $11(18.3)$ & $24(55.8)$ & \\
\hline \multicolumn{4}{|c|}{$N$ gonorrhoeae coinfection } \\
\hline Yes & $27(45.0)$ & $3(7.0)$ & \multirow[t]{2}{*}{$0.000^{*}$} \\
\hline No & $33(55.0)$ & $40(93.0)$ & \\
\hline \multicolumn{4}{|c|}{$T$ pallidum coinfection } \\
\hline Yes & $5(8.3)$ & $2(4.7)$ & \multirow[t]{2}{*}{0.696} \\
\hline No & $55(91.7)$ & $41(95.3)$ & \\
\hline \multicolumn{4}{|c|}{ Human papillomavirus coinfection } \\
\hline Yes & $6(10.0)$ & $3(7.0)$ & \multirow[t]{2}{*}{0.592} \\
\hline No & $54(90.0)$ & $40(93.0)$ & \\
\hline \multicolumn{4}{|c|}{ HIV coinfection } \\
\hline Yes & $5(8.3)$ & $0(0,0)$ & \multirow[t]{2}{*}{0.073} \\
\hline No & $55(91.7)$ & $43(100)$ & \\
\hline \multicolumn{4}{|c|}{ C trachomatis serovar } \\
\hline B & $0(0,0)$ & $2(4.7)$ & \multirow[t]{9}{*}{$0.042^{*}$} \\
\hline $\mathrm{D} / \mathrm{Da}$ & $10(16.7)$ & $2(4.7)$ & \\
\hline $\mathrm{E}$ & $24(40.0)$ & $16(37.2)$ & \\
\hline $\mathrm{F}$ & $11(18.3)$ & $3(7.0)$ & \\
\hline G & $10(16.7)$ & $14(32.6)$ & \\
\hline H & $0(0.0)$ & $2(4.7)$ & \\
\hline 1/la & $2(3.3)$ & $0(0.0)$ & \\
\hline$J$ & $2(3.3)$ & $3(7.0)$ & \\
\hline $\mathrm{K}$ & $1(1.7)$ & $1(2.3)$ & \\
\hline
\end{tabular}

${ }^{*}$ Statistically significant $(\mathrm{p}<0.01)$. 